\title{
Resistencia a carbapenemes asociada a integrones clase 1 en Pseudomonas aeruginosa
}

\author{
María Fernanda Yauri ${ }^{1}$, Iliana Alcocer ${ }^{1}$, Jeannete Zurita ${ }^{2}$ \& Mercedes Rodríguez-Riglos $^{1}$ \\ ${ }^{1}$ Laboratorio de Microbiología, Escuela de Ciencias Biológicas, PUCE, \\ Quito, Ecuador. iralcocer@puce.edu.ec \\ ${ }^{2}$ Departamento de Microbiología, Zurita\&Zurita Laboratorios, Quito, Ecuador \\ Recibido: 2010-05-27, aprobado: 2010-08-31.
}

RESUMEN: Pseudomonas aeruginosa es un microorganismo, oportunista de humanos, comúnmente aislado de infecciones nosocomiales. Es difícil de tratar por su inherente resistencia a varios antibióticos y por su rápida adquisición de genes de resistencia. En los últimos años han sido reportados aislados multiresistentes de $P$. aeruginosa con genes que codifican enzimas que confieren resistencia a los carbapenemes: las metalo- $\beta$-lactamasas (MBLs). Estos genes, comúnmente, se encuentran localizados en integrones. El objetivo del estudio fue identificar genes que codifican metalo- $\beta$-lactamasas (MBLs) y su ubicación en integrones clase 1 en aislados clínicos de $P$. aeruginosa. Se colectaron 129 aislados clínicos en Zurita\&Zurita Laboratorios entre enero de 2005 a diciembre de 2008. La detección de genes que codifican MBLs se realizó por PCR, amplificando los genes mayormente diseminados entre bacilos Gram negativos no fermentadores productores de MBLs y encontrados en Latinoamérica: bla $\mathrm{V}_{\mathrm{IM}}$, bla $a_{\mathrm{IMP}}$ y bla $_{\mathrm{SPM}}$. La ubicación de estos genes en integrones clase 1 fue determinada por PCR anidado. De los 129 aislados analizados, 46 aislados fueron resistentes a carbapenemes. De los 46 aislados resistentes $34(73,9 \%)$ presentaron genes que codifican MBLs y el 14,7\% estuvieron ubicados en integrones clase 1. Fue evidente la alta prevalencia de genes productores de MBLs en la población estudiada.

PALABRAS CLAVE: Carbapenemes, integrones, metalo- $\beta$-lactamasas, multiresistencia, Pseudomonas aeruginosa.

ABSTRACT.- Pudomonas aeruginosa is a microbial agent, human opportunistic and commonly isolated from nosocomial infections. It is a difficult organism to treat because of its inherent resistance to various antibiotics and rapid acquisition of resistance genes. In recent years, it has been reported multiresistant isolates of $P$. aeruginosa with genes that encode enzymes which confer principally resistance 
to carbapenems: metallo- $\beta$-lactamases (MBLs). These genes are often located in integrons. Its importance lies in the spread of resistance genes between Gram-negative bacteria. The aim of this study was to identify genes that encode metallo- $\beta$ lactamases (MBLs) and their location in class 1 integrons in clinical isolates of $P$. aeruginosa. The 129 clinical isolates were collected in Zurita\&Zurita Laboratories between 2006 and 2008. The detection of genes that encode MBLs was performed by PCR, amplifying the genes mostly scattered among non-fermenting Gram negative bacilli that produce MBLs: bla ${ }_{\mathrm{VIM}}$, bla $_{\mathrm{IMP}}$ and bla $_{\mathrm{SPM}}$. The location of these genes in class 1 integrons was determined by nested PCR. Of the 129 isolates analyzed, 46 were resistant to carbapenems. Of the 46 resistant isolates, 34 (73.9\%) had genes encoding MBLs. Only $14.7 \%$ were located in class 1 integrons. It was evident the high prevalence of MBLs producing genes in the population studied.

KEYWORDS: Carbapenems, integrons, metallo- $\beta$-lactamase, multiresistance, Pseudomonas aeruginosa.

INTRODUCCIÓN.- Pseudomonas aeruginosa es una bacteria aerobia, Gram negativa, no fermentadora ni formadora de esporas, móvil por la presencia de flagelos lofótricos y miembro de la familia Pseudomonadaceae. Es un patógeno oportunista comúnmente asociado a personas inmunocomprometidas que presentan infecciones en pulmones, oído, válvulas cardíacas, tracto urinario, sistema nervioso central, piel y en heridas quirúrgicas. Adquiere especial importancia en pacientes con fibrosis quística (1). El programa Internacional de Control de las Infecciones Nosocomiales (INICC) describe a las infecciones nosocomiales como uno de los mayores problemas sanitarios, siendo de particular importancia las infecciones causadas por bacterias multiresistentes (2). Además, establece que la mayor pre- valencia mundial de infecciones intrahospitalaria corresponde a América Latina, donde el 11,4\% de los aislados obtenidos son de $P$. aeruginosa (3).

Pseudomonas aeruginosa es inherentemente resistente a una amplia variedad de antisépticos y antibióticos como cefalosporinas de primera y segunda generación, tetraciclinas, cloranfenicol, macrólidos, novobiocina; dejando como última alternativa de tratamiento al grupo de los carbapenemes (4). Los carbapenemes son los antimicrobianos $\beta$-lactámicos en la terapia contra $P$. aeruginosa mayormente empleados. Sin embargo, durante la última década, la aparición de nuevos factores de resistencia ha elevado el número de aislados resistentes a estos antibióticos (5 y 6). 
La resistencia en $P$. aeruginosa a los carbapenemes es generada por múltiples mecanismos, tales como: bombas de flujo, mutación de porinas, producción de enzimas que hidrolizan al antibiótico. Este estudio se centró en este último mecanismo: la producción de metalo- $\beta$-lactamasas (MBLs; 7). Las MBLs son enzimas bacterianas con una elevada actividad hidrolítica que inactivan a todos los antibióticos $\beta$-lactámicos (penicilinas, cefalosporinas y carbapenemes), transformando a estos agentes terapéuticos en compuestos inofensivos para las bacterias (8). Las más comunes y ampliamente reportadas MBLs son las tipo VIM e IMP, las cuales exhiben una amplia distribución a nivel mundial con más de 50 variantes alélicas descritas (9 y 10). Los genes que codifican enzimas tipo MBLs son, generalmente, transferidos por determinantes genéticos móviles como son los plásmidos o transposones, los cuales a su vez pueden contener sistemas de recombinación sitio-específica denominados integrones (11). Esto sumado a su frecuente relación con otros genes que confieren resistencia a diversas familias de antibióticos (como aminoglucósidos), convierten a estos aislados en un importante problema terapéutico a nivel hospitalario (12).

Los primeros aislados resistentes a carbapenemes y productores de MBLs fueron registrados en la década de los 80 en Asia y Europa (8). En Latinoamé- rica no fueron encontradas sino hasta el 2003, siendo descritas por primera vez en Chile y Venezuela (13).

Las MBLs han sido descritas y clasificadas en cuatro tipos clínicamente relevantes: IMP reportada en Japón (14), VIM detectada originalmente en Italia (15); GIM observada en Alemania (16) y SPM descubierta en Sao Paulo, Brasil (17).

Diversos estudios de genes que codifican MBLs demostraron su ubicación como genes "cassette" en integrones clase 1 (18). Los integrones son sistemas formados de dos segmentos conservados y separados por una región variable capaz de insertar y escindir genes en "cassettes" (19). Los genes en "cassette" son elementos móviles extracromosómicos circularizados que no se expresan hasta que son insertos en un integrón. Los integrones son movilizados por transposición en plásmidos $\mathrm{y}$ transposones (19).

En el Ecuador no existen datos que demuestren el estudio de la resistencia en Gram negativos no fermentadores. Así, este trabajo contribuye en el conocimiento de la multiresistencia, la presencia de genes relacionados con la resistencia y su relación con integrones clase 1. El objetivo de este estudio fue identificar los genes relacionados con la resistencia a carbapenemes tipo metalo- $\beta$-lactamasas y su ubicación en integrones clase 1 en aislados clínicos de Pseudomonas aeruginosa resistentes 
a imipenem y meropenem. Los objetivos específicos fueron: a) Identificar fenotípica y genotípicamente los aislados de Pseudomonas aeruginosa mediante pruebas bioquímicas y moleculares como la Reacción en Cadena de la Polimerasa (PCR) por amplificación del gen de la proteína de la membrana externa oprL. b) Detectar la presencia de genes productores de metalo- $\beta$-lactamasas (MBLs) mediante PCR. c) Determinar la localización de los genes que codifican metalo- $\beta$-lactamasas a través de la amplificación de la región variable de integrones clase 1 .

\section{MATERIALES Y MÉTODOS} Aislamientos bacterianos

Se analizaron 129 aislados de $P s e u-$ domonas aeruginosa recibidas de la colección del Departamento de Microbiología de los laboratorios Zurita \& Zurita y tomados de muestras clínicas de pacientes atendidos en diversos centros hospitalarios de Quito. El período de colección de los aislados fue comprendido entre enero de 2005 a diciembre de 2008. La identificación y el perfil de resistencia fueron obtenidos mediante MicroScan (VITEK) siguiendo las especificaciones del fabricante.

\section{Caracterización fenotípica y genotípica de Pseudomonas aeruginosa}

Pseudomonas aeruginosa de acuerdo a sus reacciones bioquímicas se identifica como un bacilo Gram negativo móvil, no fermentador de azúcares, oxidasa positiva, productora de ornitina descarboxilasa, no productora de triptofanasas y sintetizadora de lisina descarboxilasa. Para evidenciar este perfil se realizaron las pruebas bioquímicas estándares: Agar con triple azúcar y hierro (TSI), Motilidad, Indol, Ornitina (MIO), Motilidad, indol, lisina (MILI), óxido fermentación (O-F).

La confirmación molecular de los aislados se realizó mediante la técnica de PCR amplificando el gen que codifica la proteína $o p r L$ de la membrana externa, empleando los iniciadores y condiciones descritos por $\mathrm{Xu}$ et al. (20): F 5' ATGGAAATGCTGAAATTCGGC 3' y R 5'CTTCTTCAGCTCGACGCGACG 3'.

El templado fue preparado mediante kit de extracción de ADN genómico (PROMEGA nro. A1120). La reacción se preparó en un volumen final de 25 $\beta 1$, conteniendo $1,25 \mathrm{U}$ de Taq polimerasa (PROMEGA nro.M8295) $0,1 \mathrm{mM}$ de cada dNTP, 2,5 $\mathrm{mM}$ de $\mathrm{MgCl} 2,3,5$ $\mathrm{mM}$ de $\mathrm{KCl}, 0,1 \mu \mathrm{M}$ de cada iniciador y $4 \mu \mathrm{l}$ de ADN templado en tampón para PCR 1X. La amplificación se realizó en un termociclador GeneAmp PCR system 9700 (Perkin Elmer). El programa de PCR consistió en 35 ciclos de $96{ }^{\circ} \mathrm{C}$ por 1 minuto, $55^{\circ} \mathrm{C}$ por 1 minuto y $72{ }^{\circ} \mathrm{C}$ por un minuto, seguido de un paso de extensión final de $72{ }^{\circ} \mathrm{C}$ por diez minutos. 
Los productos de PCR se sometieron a electroforesis en geles de agarosa (Invitrogen) al $1 \%$ a $125 \mathrm{~V} / \mathrm{cm}$ por 60 min en tampón $44,5 \mathrm{mM}$ tris- $\mathrm{HCl}$, 44,5 $\mathrm{mM}$ ácido bórico, 1,5 $\mathrm{mM}$ EDTA (TBE). Se empleó como marcador molecular ADN de 100 pb (Invitrogen). Los geles fueron teñidos empleando Syber gold 10.000x en DMSO (Invitrogen). Los productos de amplificación se analizaron en Safe Imager (Invitrogen) por examen visual considerando todas las bandas visibles, independientemente de su intensidad.

\section{Detección de genes que codifican MBLs}

La detección de genes productores de MBLs se realizó por PCR. Fueron analizados los dos genes más frecuentemente encontrados entre bacilos Gram negativos no fermentadores y un gen reportado únicamente para Latinoamérica (7 y 10).

Los iniciadores empleados para el gen blaviM fueron: F 5' GTTTGG TCGCATATCGCAAC $3^{\prime}$ y $\mathrm{R} \quad 5^{\prime}$ AATGCGCAGCACCAGGATAG 3' (21); para el gen blaIMP los iniciadores empleados fueron F 5' GAAGGYGTT$\begin{array}{lllll}\text { TATGTTCATAC } & 3^{\prime} & \text { y } & \mathrm{R} & 5^{\prime}\end{array}$ GTAMGTTTCAAGAGTGATGC 3' (10); y para el gen blaspM se usaron los iniciadores $\mathrm{F}$ 5' CTGCTTGGATTC ATGGGCGC 3` y blaspm R 5' CCTTTT CCGCGACCTTGATC 3’
(21). Las condiciones de amplificación fueron las descritas por Pitaut et al. (21).

El templado fue preparado mediante kit de extracción de ADN genómico (PROMEGA No. A1120). La reacción se preparó en un volumen final de 25 $\mu 1$, conteniendo $1 \mathrm{U}$ de $T a q$ polimerasa (PROMEGA No.M8295), 0,16 mM de cada dNTP, 1,5 $\mathrm{mM}$ de $\mathrm{MgCl}_{2}, 0,16$ $\mathrm{mM}$ de cada iniciador y $2 \mu \mathrm{l}$ de ADN templado en tampón para PCR $1 \mathrm{X}$ (PROMEGA). La amplificación se realizó en un termociclador GeneAmp PCR system 9700 (Perkin Elmer). El programa de PCR consistió de una incubación inicial de $37{ }^{\circ} \mathrm{C}$ por 10 minutos, una denaturación inicial de 94 ${ }^{\circ} \mathrm{C}$ por 5 minutos, seguido por 30 ciclos de $94{ }^{\circ} \mathrm{C}$ por 1 minuto, $54{ }^{\circ} \mathrm{C}$ por 31 minutos y un paso de extensión final de $72{ }^{\circ} \mathrm{C}$ por 1,5 minutos.

Los productos de PCR se sometieron a electroforesis con las mismas condiciones empleadas para la identificación molecular de $P$. aeruginosa.

\section{Determinación de la localización \\ de los genes que codifican MBLs}

El ADN de los aislados que resultaron positivos para la presencia de genes codificantes de MBLs fue empleado en una segunda PCR para determinar la región variable de integrones de clase 1. Los iniciadores empleados son los detallados por Pitout et al. (21). Para la reacción en cadena de la polimerasa se 
prepararon reacciones de $25 \mu 1$ conteniendo: $1 \mathrm{U}$ de $\mathrm{Taq}$ polimerasa (PROMEGA nro. M8295), 0,16 mM de cada dNTP, 1,5 mM de $\mathrm{MgCl}_{2}, 0,16 \mathrm{mM}$ de cada iniciador y $2 \mu 1$ de ADN templado en tampón para PCR 1X.

Los parámetros de amplificación fueron: $95{ }^{\circ} \mathrm{C}$ por 5 minutos; seguido de 30 ciclos de $95^{\circ} \mathrm{C}$ por 1 minuto, 52 ${ }^{\circ} \mathrm{C}$ por 1 minuto y $72{ }^{\circ} \mathrm{C}$ por 2 minutos, y un período de extensión final de 72 ${ }^{\circ} \mathrm{C}$ por 10 minutos.

Los productos resultantes de la PCR fueron separados a través de electroforesis horizontal en geles de agarosa (Invitrogen 15510-027) al 1\%.

Los productos obtenidos de las amplificaciones anteriores fueron usados como templados para la ejecución de la PCR anidada y fueron empleados iniciadores para cada uno de los genes encontrados (blavIM y blaIMP). Las cantidades y los parámetros de amplificación son los mismos descritos anteriormente.

\section{RESULTADOS}

El $100 \%$ de los aislados (129) fueron confirmados como Pseudomonas aeruginosa mediante análisis molecular del gen que codifica la proteína opr $\mathrm{L}$ de la membrana externa (Figura 1). La identificación molecular concordó con la identificación fenotípica realizada a través de pruebas bioquímicas.

De los 129 aislados estudiados, 46 mostraron resistencia a carbapenemes. Los datos del origen de los aislados resistentes se encuentran en la Tabla 1.
Los perfiles de resistencia a los carbapenemes evaluados en los 46 aislados de Pseudomonas aeruginosa mostraron un alto porcentaje de resistencia a ambos $\beta$-lactámicos empleados (imipenem y meropenem), con 34 aislados resistentes (73,9\%); nueve aislados $(19,6 \%)$ fueron resistentes únicamente a imipenem y tres $(6,5 \%)$ fueron únicamente para meropenem (Figura 2).

De los 46 aislados resistentes, 34 (73,9\%) presentaron uno o dos genes que codificaban MBLs. En los doce aislados restantes $(26,1 \%)$ no fue detectado ningún gen estudiado. De los 34 aislados portadores de genes que codifican MBLs, 24 (70,6\%) presentaron el gen blaviM, seis $(17,6 \%)$ registraron el gen bla IMP y cuatro aislados $(11,8 \%)$ presentaban ambos genes blaviM /bla IMP (Figura 3). Cinco (14,7\%) de los 34 aislados codificantes de MBLs fueron ubicados en la región variable de integrones clase 1 y $29(84,3 \%)$ no lo fueron.

De los 24 aislados que presentaron el gen blaviM, cinco $(20,8 \%)$ fueron ubicados en la región variable de integrones clase 1 (Figura 4). De los seis aislados portadores del gen blaIMP, tan solo uno (16,7\%), pudo ser situado en la región variable de integrones clase 1 (Figura 5). Finalmente, de los cuatro aislados positivos para ambos genes, dos aislados $(50 \%)$ fueron ubicados en región variable de integrones clase 1 . 


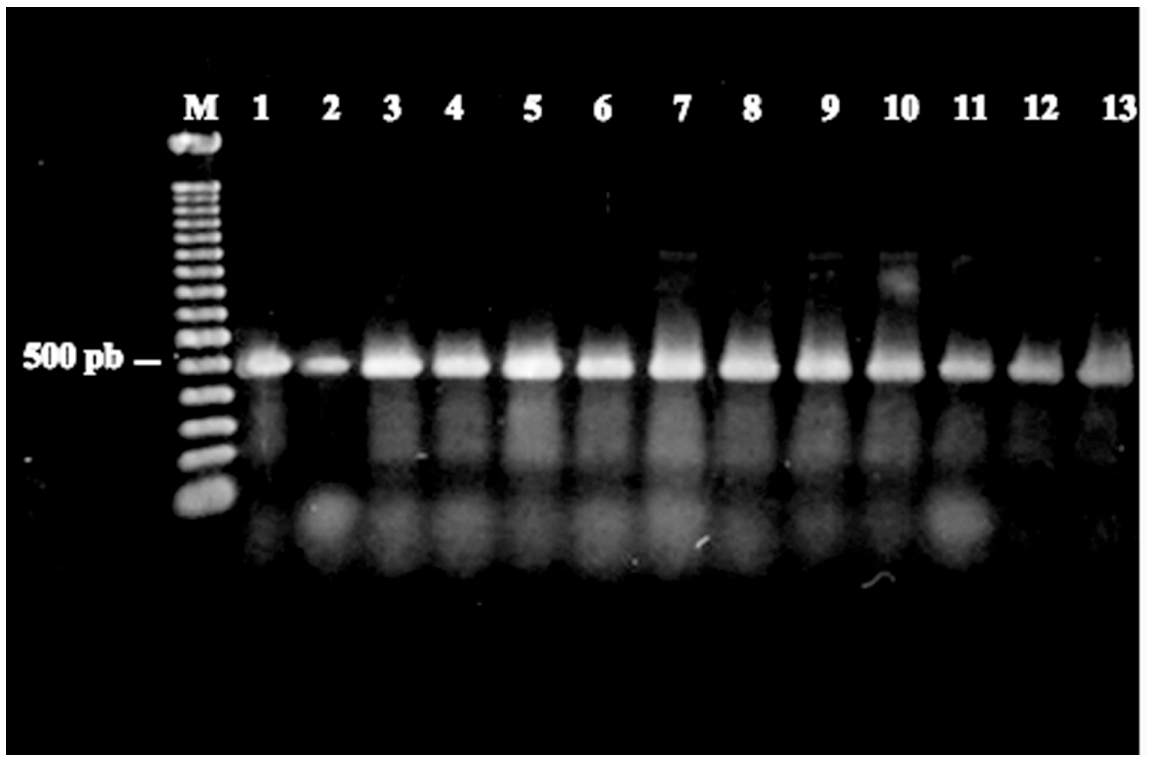

Figura 1. Representación gráfica de la identificación de la proteína de la membrana externa oprL para confirmación genotípica de Pseudomona aeruginosa. M, marcador de peso molecular 100pb; canaletas 1-13, aislados de Pseudomonas aeruginosa confirmados.

DISCUSIÓN

En los últimos años se ha observado el incremento de genes productores de MBLs asociados a integrones, los cuales a su vez se relacionan con plásmidos y transposones, facilitando su transferencia vertical a una amplia gama de agentes patógenos (11).

El estudio de la presencia de genes que codifican MBLs reveló un alto porcentaje de genes blavim (70,6\%), en los aislados analizados resistentes a carbapenemes. Datos que concuerdan con estudios previos, donde el gen blaviM, especialmente la variante alélica blaVIM-2, ha sido identificada de manera predominante en Latinoamérica y varios países alrededor del mundo $(7,9$, 12 y 22).
El gen blaimP fue registrado en un menor porcentaje $(17,6 \%)$. Anteriormente se ha descrito porcentajes similares de presencia para genes blaIMP en aislados clínicos de Pseudomonas aeruginosa resistentes a carbapenemes $(8,21$ y 24$)$.

Los aislados clínicos de $P$. aeruginosa resistentes a carbapenemes arrojaron un $0,0 \%$ de presencia de genes productores de MBLs tipo SPM, resultado que contribuye a su localización endémica al norte de Brasil (17).

Mecanismos como la baja permeabilidad para el ingreso del antibiótico por pérdida de porinas o expulsión del mismo a través de bombas de flujo podrían explicar la resistencia observada en los aislados que no pro- 
Tabla 1 Datos de origen de los aislados de Pseudomonas aeruginosa analizados en este estudio (Continuación)

\begin{tabular}{|c|c|c|c|c|c|}
\hline \multicolumn{3}{|c|}{ Bacteria } & \multicolumn{3}{|l|}{ Paciente } \\
\hline $\begin{array}{l}\text { Código de } \\
\text { Congelación }\end{array}$ & $\begin{array}{l}\text { Código } \\
\text { Hospital }\end{array}$ & $\begin{array}{l}\text { Fecha de Aislamiento } \\
\text { (años) }\end{array}$ & $\begin{array}{l}\text { Sexo } \\
\text { muestra }\end{array}$ & Edad & en de la \\
\hline 13 Ps aer & 10 & $01 / 07 / 2005$ & $\mathrm{M}$ & 2 & Herida \\
\hline 16 Ps aer & 4 & $01 / 07 / 2005$ & $\mathrm{M}$ & 5 & Biopsia \\
\hline 17 Ps aer & 7 & 08/07/2005 & $\mathrm{F}$ & 7 & Herida \\
\hline 23 Ps aer & 274 & 09/08/2005 & $\mathrm{F}$ & 16 & Herida \\
\hline 28 Ps aer & 60 & 09/09/2005 & $\mathrm{M}$ & 59 & Herida \\
\hline 29 Ps aer & 237 & $22 / 09 / 2005$ & $\mathrm{~F}$ & 19 & Esputo \\
\hline 40 Ps aer & 189 & $01 / 10 / 2005$ & $\mathrm{D}$ & ND & Absceso \\
\hline 45 Ps aer & 773 & $01 / 10 / 2005$ & D & ND & Absceso \\
\hline 48 Ps aer & 835 & $24 / 10 / 2005$ & $\mathrm{M}$ & 8 & Biopsia \\
\hline 57 Ps aer & 430 & $13 / 12 / 2005$ & $\mathrm{M}$ & 30 & Herida quirúrgica \\
\hline 95 Ps aer & 714 & $22 / 03 / 2006$ & $\mathrm{~F}$ & 79 & Herida \\
\hline 97 Ps aer & 483 & $15 / 03 / 2006$ & $\mathrm{M}$ & 6 & Hemocultivo \\
\hline 104 Ps aer & 1042 & $31 / 03 / 2006$ & $\mathrm{~F}$ & 34 & Secreción traqueal \\
\hline 130 Ps aer & 597 & $19 / 05 / 2006$ & $\mathrm{~F}$ & 40 & Secreción traqueal \\
\hline 140 Ps aer & 638 & $22 / 06 / 2006$ & $\mathrm{~F}$ & 31 & Secreción traqueal \\
\hline 142 Ps aer & 632 & $22 / 06 / 2006$ & $\mathrm{M}$ & 56 & Líquido peritoneal \\
\hline 150 Ps aer & 899 & 30/06/2006 & $\mathrm{M}$ & 26 & Secreción traqueal \\
\hline 167 Ps aer & 3532 & $22 / 08 / 2006$ & $\mathrm{~F}$ & 48 & Herida quirúrgica \\
\hline 191 Ps aer & 4149 & 03/10/2006 & $\mathrm{M}$ & ND & Absceso \\
\hline 228 Ps aer & 26 & 01/12/2006 & $\mathrm{M}$ & 36 & Secreción traqueal \\
\hline 235 Ps aer & 565 & 20/06/2007 & $\mathrm{F}$ & 2 meses & Hemocultivo \\
\hline 236 Ps aer & 945 & 28/12/2006 & $\mathrm{M}$ & 27 & Secreción traqueal \\
\hline 237 Ps aer & 942 & 28/12/2006 & $\mathrm{M}$ & 72 & Secreción traqueal \\
\hline 310 Ps aer & 4831 & $15 / 11 / 2007$ & $\mathrm{M}$ & ND & Esputo \\
\hline 319 Ps aer & 924 & $28 / 11 / 2007$ & M & 60 & Secreción traqueal \\
\hline 326 Ps aer & 256 & $08 / 12 / 2007$ & $\mathrm{~F}$ & 77 & Secreción traqueal \\
\hline 330 Ps aer & 528 & $16 / 12 / 2007$ & $\mathrm{M}$ & 21 & Secreción traqueal \\
\hline 332 Ps aer & 742 & $22 / 12 / 2007$ & M & 86 & Líquido pleural \\
\hline 333 Ps aer & 768 & $23 / 12 / 2007$ & $\mathrm{~F}$ & 80 & Secreción traqueal \\
\hline 335 Ps aer & 800 & 24/12/2007 & $\mathrm{F}$ & 61 & Herida quirúrgica \\
\hline 345 Ps aer & 963 & $29 / 12 / 2007$ & $\mathrm{~F}$ & 61 & Secreción traqueal \\
\hline 346 Ps aer & 975 & 30/12/2007 & M & 61 & Esputo \\
\hline 355 Ps aer & 183 & 06/03/2008 & M & ND & Urocultivo \\
\hline 362 Ps aer & 595 & $26 / 09 / 2008$ & $\mathrm{~F}$ & 22 & Secreción traqueal \\
\hline 365 Ps aer & 466 & 26/09/2008 & $\mathrm{F}$ & ND & Esputo \\
\hline 377 Ps aer & 332 & $26 / 09 / 2008$ & M & ND & Secreción traqueal \\
\hline 381 Ps aer & 334 & $30 / 09 / 2008$ & $\mathrm{~F}$ & ND & Herida \\
\hline 385 Ps aer & 467 & $30 / 09 / 2008$ & M & 46 & Secreción traqueal \\
\hline 387 Ps aer & 531 & $30 / 09 / 2008$ & M & 8 & Herida quirúrgica \\
\hline 403 Ps aer & 792 & $30 / 09 / 2008$ & M & 77 & Secreción traqueal \\
\hline 411 Ps aer & 944 & $30 / 09 / 2008$ & $\mathrm{~F}$ & ND & Herida quirúrgica \\
\hline 413 Ps aer & 153 & $30 / 09 / 2008$ & M & 74 & Hemocultivo \\
\hline 429 Ps aer & 818 & $01 / 10 / 2008$ & $\mathrm{~F}$ & ND & Herida quirúrgica \\
\hline 437 Ps aer & 508 & $02 / 10 / 2008$ & M & ND & Herida quirúrgica \\
\hline 438 Ps aer & 170 & $01 / 10 / 2008$ & M & 26 & Secreción traqueal \\
\hline 443 Ps aer & 3560 & $01 / 10 / 2008$ & $\mathrm{~F}$ & 75 & Esputo \\
\hline
\end{tabular}

F, femenino; M, masculino; ND, no determinado 


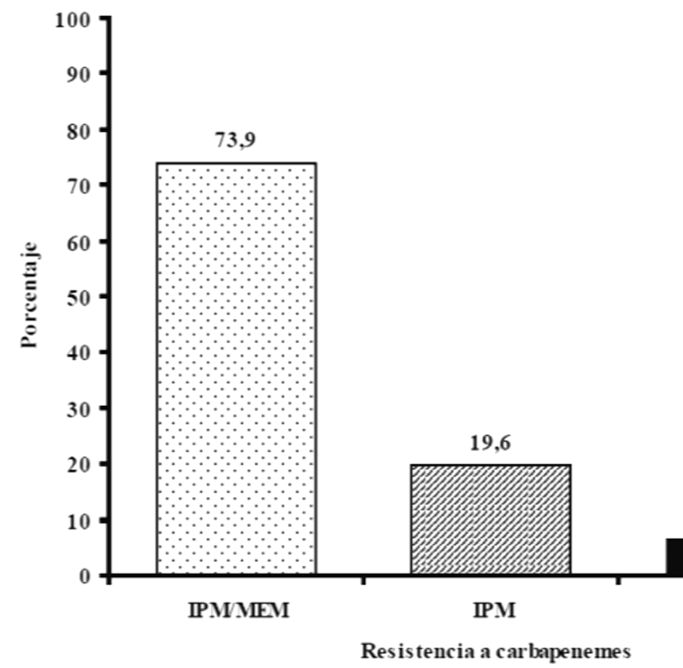

ducían MBLs (7). Estos mecanismos no fueron analizados en el presente trabajo.

En cuanto a la ubicación de los genes que codifican MBLs, el estudio demostró que fueron pocos los aislados de $P$. aeruginosa, alrededor del $14,0 \%$, encontrados como "cassettes" génicos en la región variable de integrones clase 1 ; a pesar de encontrarse a estos elementos genéticos ampliamente distribuidos entre los bacilos Gram negativos no fermenteadores $(19,23)$.

La presencia del "cassette" portador del gen blavIM y blaIMP en un integrón no confiere movilidad por sí solo, pero sí pueden encontrarse insertos en elementos genéticos móviles como plásmidos y transposones. Los integrones al encontrarse asociados a plataformas genéticas móviles incrementan su diseminación y transferencia intra e interespecífica (18).
Figura 2. Porcentaje de resistencia a carbapenemes en aislados clínicos de Pseudomonas aeruginosa.

MIEM

\section{CONCLUSIONES}

Los 129 aislados clínicos fueron confirmados como Pseudomonas aeruginosa mediante pruebas bioquímicas.

La identificación genotípica de Pseudomonas aeruginosa mediante la reacción en cadena de la polimerasa (PCR) fue positiva para los 129 aislados.

La mayoría de aislados resistentes a carbapenemes, imipenem y meropenem $(73,9 \%)$, presentaron genes que codifican metalo- $\beta$-lactamasas.

Los genes blaviM y blaIMP fueron encontrados en la mayoría de aislados resistentes a carbapenemes en un $70,6 \%$ y $17,6 \%$, respectivamente. Un bajo porcentaje de aislados presentaron ambos genes. El gen bla $\mathrm{SPM}$ no fue encontrado en ningún aislado resistente de origen hospitalario.

Un considerable porcentaje del total de los aislados resistentes a carbapenemes fueron ubicados en integrones clase 1 . 


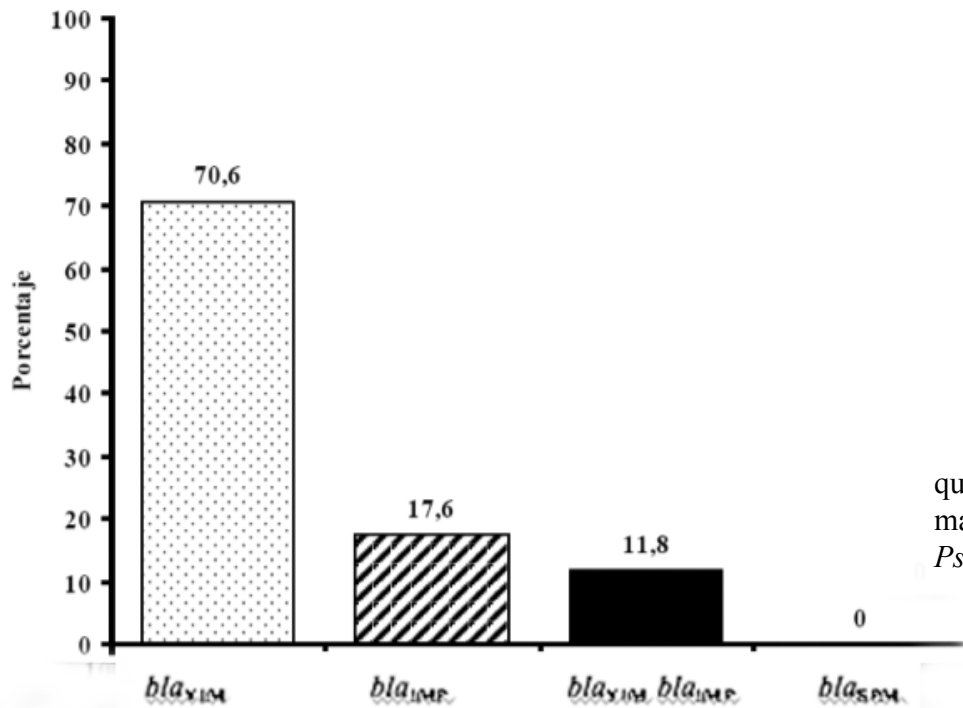

Genes de metalo- $\beta$-lactamasas

Figura 4. Representación gráfica de electroforesis de los genes blaVIM y blaIMP de aislados de Pseudomonas aeruginosa resistentes a carbapenemes. Canaletas 1, integrón; canaleta 2 y 4 , integrón y gen bla $\mathrm{VIM}_{\mathrm{M}}$; canaleta 3 , gen bla $\mathrm{VIM}$; canaleta 5, marcador de peso molecular $100 \mathrm{pb}$; canaletas 6 y 7 , control negativo y canaleta 8 , gen blaIMP
Figura 3. Porcentaje genes que codifican metalo- $\beta$-lactamasas en aislados clínicos de Pseudomonas aeruginosa.

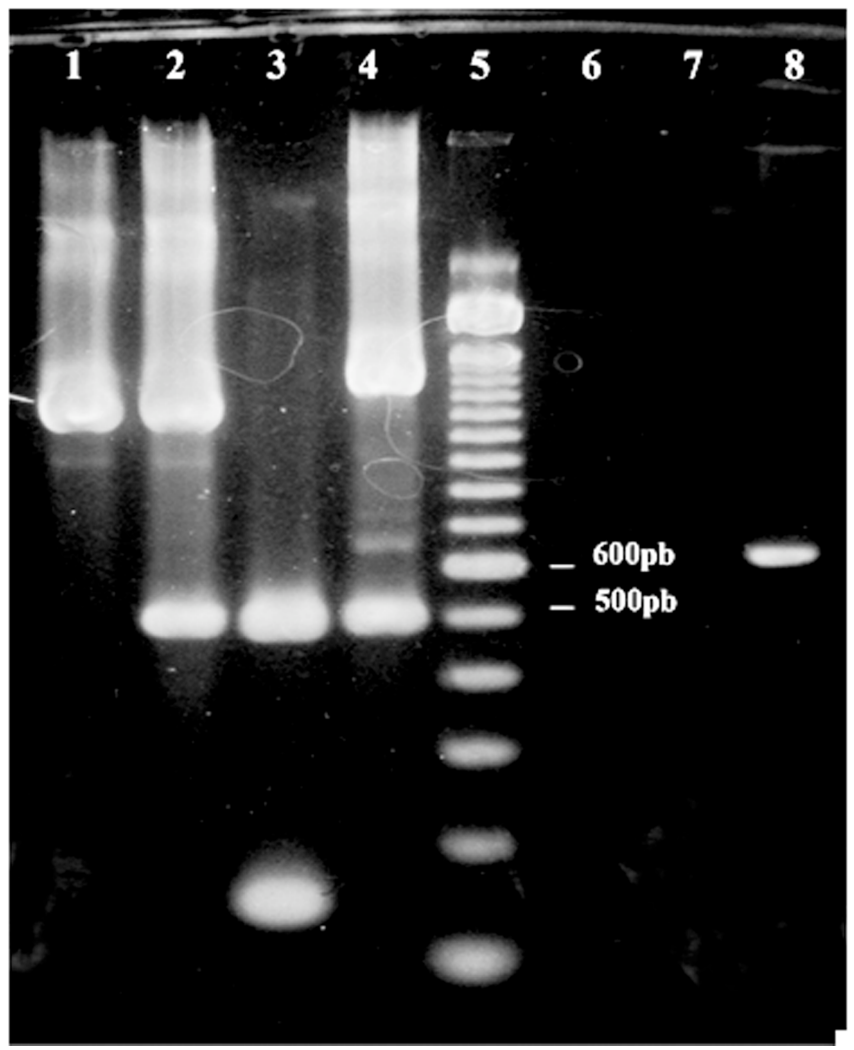

Revista Ecuatoriana de Medicina y Ciencias Biológicas - Vol. XXXI Números 1 y 2: 20-32, octubre 2010 


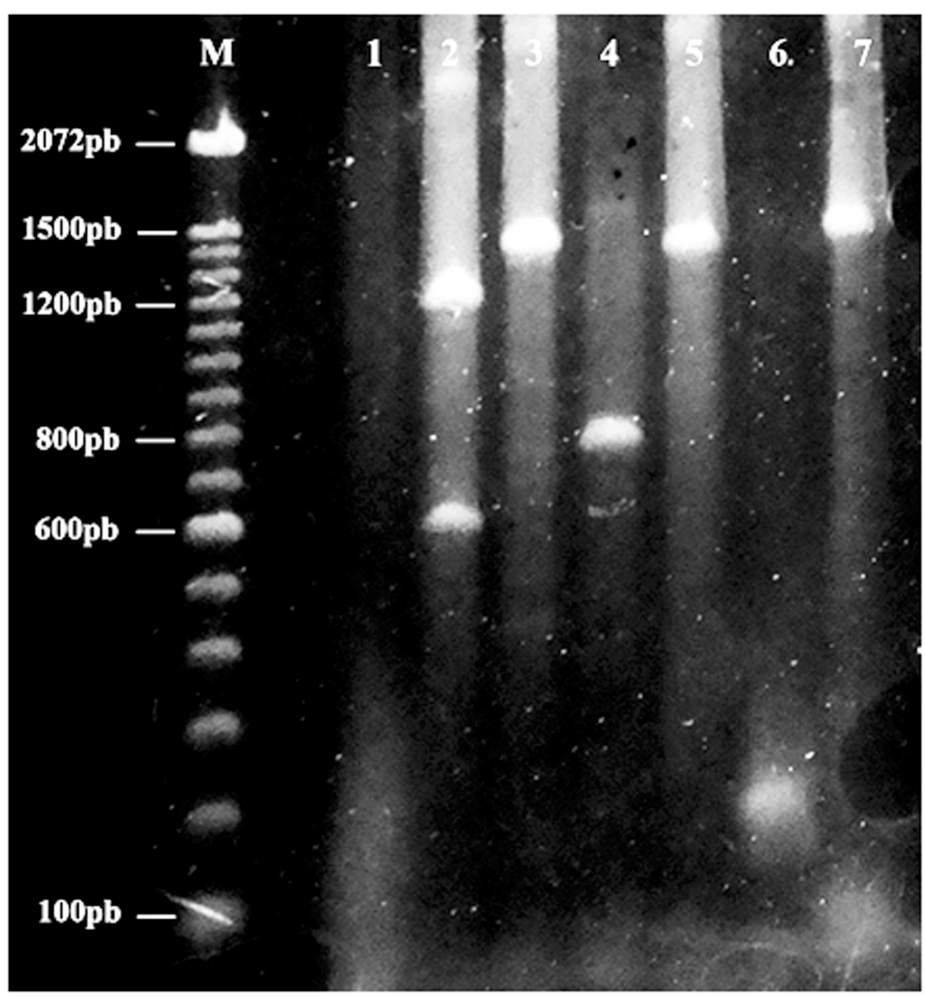

Figura 5. Representación gráfica de eletroforesis del gen blaIMP de aislados de Pseudomonas aeruginosa resistentes a carbapenemes. M, marcador de peso molecular $100 \mathrm{pb}$; canaleta 1 , control negativo; canaleta 2 , integrón y gen bla $\mathrm{IMP}$; canaleta 3,4 y 5, integrón; canaletas 6 ausencia integrón y canaleta 7 integrón.

\section{LITERATURA CITADA}

1. RUIZ, S. 2007. Pseudomonas aeruginosa: Aportación al conocimiento de su estructura y al de los mecanismos que contribuyen a su resistencia a los antimicrobianos. Tesis de Doctorado, Universidad de Barcelona. Barcelona, España.

2. ROSENTHAL, D.; MAKI DG, L.; MEHTA, A.; ALVAREZMORENO, C.; HIGUERA, F.; CUELLAR, L.; MADANI, N. 2008. International Nosocomial
Infection Control Consortium report, data summary for 20022007, issued January 2008. American Journal of Infection Control. 36: 627-637.

3. CANO, M.; DOMÍNGUEZ, M.; EZPELETA, C.; PADILLA, B.; RAMÍREZ, E.; MARTÍNEZ, L. 2008. Cultivos de vigilancia epidemiológica de bacterias resistentes a los antimicrobianos de interés nosocomial. Enfermedades Infecciosa y Microbiología Clínica. 26: 220-229. 
4. RAHAL, J. 2008. The role of carbapenems in initial therapy for serious Gram negative infections. BioMed Central LTD. 12 (Suppl 4).

5. OLIVER, A. 2009. Impacto de la diseminación de Pseudomonas aeruginosa multiresistente productora de metalo- $\beta$-lactamasas en los hospitales: presente y futuro. Enfermedades Infecciosas y Microbiología Clínica. 27: 255-256.

6. PFEIFER, Y.; CULLIK, A.; WITTE, W. 2010. Resistance to cephalos-porins and carbapenems in Gram-negative bacterial pathogens. International Journal of Medical Microbiology. 34: 235-240.

7. ANDRADE, V. 2005. Emergencia de la resistencia a carbapenemes en Pseudomonas aeruginosa productora de metalo-- $\beta$-lactamasas. Bioquimia. 30: 52-58.

8. WALSH, T.; TOLEMAN, M.; POIREL, L.; NORDMANN, P. 2005. Metallo- $\beta$-lactamase: the Quiet before the Storm? Clinical Microbiology Reviews. 18: 306-325.

9. AUBRON, C.; POIREL, L.; FORTINEAU, N.; NICOLAS, P.; COLLET, L.; NORDMANN, P. 2005. Nosocomial spread of Pseudomonas aeruginosa isolates expressing the metallo- $\beta$-lactamase VIM-2 in a hematology unit of a French hospital. Microbial Drug Resistance. 11:254-259.

10. PAGNIEZ, G.; RADICE, M.; CUIROLO, A.; RODRÍGUEZ, O.; RODRÍGUEZ, H.; CAY, C.; FAMIGLIETTI, A.; GUTKIND, G.
2006. Prevalencia de metalo- -lactamasas a carbapenemes en un hospital Universitario de Buenos Aires. Revista Argentina de Microbiología. 38: 33-37.

11. GILLINGS, M.; BOUCHER, Y.; LABBATE, M.; HOLMES, A.; KRISHNAN, S.; HOLLEY, M.; STOKES, W. 2008. The Evolution of class 1 Integrons and the Rise of Antibiotic resistance. Journal of Bacteriology. 190: 5095-5100.

12. LOLANS, K.; QUEENAN, A.; BUSH, K.; SAHUD, A.; QUINN, J. 2005. First Nosocomial outbreak of Pseudomonas aeruginosa producing an Integron-borne Metallo- $\beta$-lactamase (VIM-2) in the United States. Journal of Antimicrobial Chemotherapy. 49: 3538-3540.

13. SÁNCHEZ, D.; MARCANO, D.; SPADOLA, E.; LEÓN, L.; PAYARES, D.; UGARTE, C.; SALGADO, N.; GUEVARA, A.; TORRES, S.; RODRÍGUEZ, J.; FLORES, R. 2008. Metaloenzimas tipo VIM detectadas en aislamientos clínicos en Pseudomonas aeruginosa en cuatro hospitales en Venezuela. Revista del Instituto Nacional de Higiene Rafael Rangel. 39 (2).

14. OSANO, E.; ARAKAWA, Y.; PORN, R.; OHTA, M. 2004. Molecular Characterization of an Enterobacterial Metallo- $\beta$-lactamase found in a clinical isolate of Serratia marcescens that shows Imipenem resistance. Antimicrobial Agents and Chemotherapy. 38: 71-78. 
15. LAURETTI, L.; RICCIO, A.; MAZZARIOL, G.; CORNAGLIA, G.; AMICOSANTE, R.; FONTANA, R.; ROSSOLINI, G. 2000. Cloning and Characterization of bla $\mathrm{VIM}_{\mathrm{M}}$, a new integron-borne metallo- $\beta$-lactamase gene from Pseudomonas aeruginosa clinical isolate. Journal of Antimicrobial Chemotherapy. 43: 1584-1590.

16. CASTANHEIRA, M.; TOLEMAN, M.; JONES, R.; SCHMID, F.; WALSH, T. 2004. Molecular characterization of a $-\beta$-lactamase gene, bla ${ }_{\mathrm{GIM}-1}$ enconding a new subclass of Metallo-b-lactamase. Antimicrobial agents and Chemotherapy. 48: 4654-4661.

17. MAGALHAES, V.; LINS, A.; MAGALHAES, M. 2005. Metallob-lactamase producing Pseudomonas aeruginosastrains isolated in Hospitals in Recife, PE, Brazil. Brazilian Journal of Microbiology. 36: 123-125.

18. IYOBE, S.; YAMADA, H.; MINAMI, S. 2006. Insertion of a carbapenemase gene cassette into an integron of a Pseudomonas aeruginosa plasmid. Journal Antimicrobial Chemotherapy. 39: 824-829.

19. XU, Z.; LI, L.; SHIRTLIFF, M.; ALAM, M.; YAMASAKI, S.; SHI, L. 2009. Ocurrence and Characteristics of Class 1 and 2 Integrons in Pseudomonas aeruginosa isolates from patients in Southern China. Journal of Clinical Microbiology. 47: 230-234.

20. XU, J.; MOORE, J.; MURPHY, P.;
MILLAR, C.; ELBORN, J. 2006. Early detection of Pseudomonas aeruginosa - comparison of conventional versus molecular (PCR) detection directly from adult patients with cystic fibrosis (CF). Annals of Clinical Microbiology and Antimicrobials. 3: 21-25.

21. PITOUT, J.; GREGSON, D.; POIREL, L. 2005. Detection of Pseudomonas aeruginosa producing Metallo- $\beta$-Lactamases in a large centralized laboratory. Journal of Clinical Microbiology. 43: $3129-3135$.

22. SIARKOU, V.; VITTI, D.; PROTONOTARIOU, E.; IKONOMIDIS, A.; SOFIANOU, D. 2009. Molecular epidemiology of Outbreak related Pseudomonas aeruginosa strains carrying the novel variant bla VIM-17 Metallo- $\beta$-lactamase gene. Antimicrobial Agents and Chemotherapy. 53: 1325-1330.

23. GOOTZ, T. 2010. The global problem of antibiotic resistance. Critical Reviews in Immunology. 30: 79-93.

24. GIBB, A.; TRIBUDDHARAT, R.; MOORE, T.; LOUIE, W.; KRULICKI, D.; LIVERMORE, M.; PALEPOU, F.; WOODFORD, N. 2002. Nosocomial outbreak of $\mathrm{c}$ a r b a p e n e m-res i s t a n t Pseudomonas aeruginosa with a new bla IMP allele, bla IMP-7. Antimicrobial Agents and Chemotherapy. 46: 255-258. 